\title{
Hemolytic Anemia with Fragmented Red Blood Cells Following Vascular Access Grafting for Hemodialysis in a Patient with Chronic Kidney Disease
}

Tohru Inaba $^{1 *}$, Yu Okamoto ${ }^{2}$, Satoshi Yamazaki ${ }^{3}$, Tohru Takatani ${ }^{4}$, Nodoka Satoh ${ }^{3}$, Masaya Nishida ${ }^{3}$, Masato Nishimura $^{4}$, Tetsuya Hashimoto ${ }^{3}$ and Hiroyuki Kobayashi ${ }^{3}$

${ }^{1}$ Department of Infection Control and Laboratory Medicine, Kyoto Prefectural University of Medicine, Japan

${ }^{2}$ Department of Anesthesiology, Tojinkai Hospital, Kyoto, Japan

${ }^{3}$ Department of Urology, Tojinkai Hospital, Kyoto, Japan

${ }^{4}$ Department of Internal Medicine, Tojinkai Hospital, Kyoto, Japan

\begin{abstract}
A 57-year-old male who had been treated with hemodialysis due to end-stage chronic kidney disease for 3 years received arterio-venous bypass grafting with a polyurethane vascular access graft in his left upper arm. Two months later, he was diagnosed with hemolytic anemia with fragmented red blood cells (RBC). He had never shown clinical symptoms such as fever or neurological abnormalities characteristic of thrombotic thrombocytopenic purpura (TTP). Moreover, neither thrombocytopenia nor coagulation abnormality was found on routine laboratory examination. He received arterial banding to reduce the blood flow entering the artificial vascular access graft, which led to rapid recovery from hemolytic anemia, without recurrence. This was an extremely rare case of angiopathic hemolytic anemia with fragmented RBC caused by unfavorable bypass grafting, successfully treated with simple reoperation to reduce the blood flow entering the vascular access graft.
\end{abstract}

Keywords: Fragmented red blood cells (RBC); Angiopathic hemolytic anemia; Arterio-venous bypass grafting; Artificial vascular access graft; Hemodialysis

\section{Introduction}

Previously, hemolytic anemia with fragmented red blood cells (RBC) was a major problem in patients treated with hemodialysis, caused by roller pumps responsible for moving blood through the hemodialyzer [1]. Although this problem has been eliminated by technological improvement, hemolytic anemia can still develop in hemodialysis patients due to various causes, such as contamination of the dialysis water, metabolic derangements arising from renal failure, or microangiopathy $[1,2]$. On the other hand, hemolytic anemia with fragmented $\mathrm{RBC}$ has also been reported in patients who underwent the major cardiovascular surgeries, such as aortic valve replacement or aortofemoral bypass grafting $[3,4]$. In this paper, we present a rare case of hemolytic anemia with fragmented RBC that occurred after arteriovenous bypass grafting in the upper arm, successfully treated by simple reduction of the blood inflow.

\section{Case Report}

A 57-year-old male, who had been treated with hemodialysis for 3 years due to end-stage chronic kidney disease caused by membranoproliferative glomerulonephritis, experienced shunt failure in August 2011. Therefore, he received surgery for brachial arteriovenous bypass with a polyurethane vascular access graft (Thratec VAG; Thoratec, CA, U.S.A.) in his left upper arm [5]. His hemoglobin (Hb) level had been well controlled at about $10-11 \mathrm{~g} / \mathrm{dL}$ with intravenous erythropoietin- stimulating agents until he received the bypass surgery. The serum lactate dehydrogenase (LDH) level was also within the normal range (121-245 U/L) at that time. However, after receiving the surgery, his $\mathrm{Hb}$ level gradually decreased, and he felt fatigue and dyspnea on effort in October 2011. Laboratory findings at that time were as follows: RBC, $1.99 \times 10^{12} / \mathrm{L}$, with $1.7 \%$ reticulocytes; $\mathrm{Hb}, 6.9$ g/dL; platelets, $233 \times 10^{9} / \mathrm{L}$; white blood cells, $5.5 \times 10^{9} / \mathrm{L}$, with normal differentials; serum LDH, 1,298 U/L; serum aspartate aminotransferase, $59 \mathrm{U} / \mathrm{L}$ (10-40 U/L); serum alanine aminotransferase, $18 \mathrm{U} / \mathrm{L}$ (5-40 $\mathrm{U} / \mathrm{L})$; and serum haptoglobin less than $10 \mathrm{mg} / \mathrm{dL}$ (19-170 mg/dL). A peripheral blood smear showed anisocytosis with microspherocytes and fragmented RBC (3\%) (Figure 1). He also experienced insomnia due to noisy bruit of his left upper arm. However, he never showed clinical symptoms such as fever or neurological abnormalities characteristic of thrombotic thrombocytopenic purpura (TTP). Coagulation abnormality was also not found on routine laboratory examination,

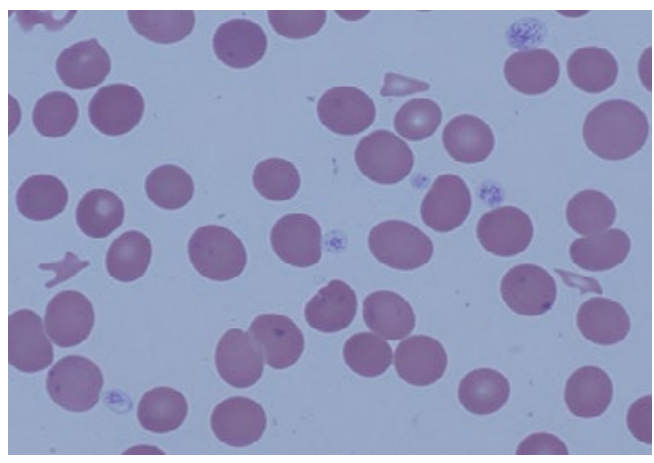

Figure 1: Fragmented red blood cells in the peripheral blood of the present patient (Wright-Giemsa staining, original magnification $\times 1,000$ ).

*Corresponding author: Tohru Inaba, Department of Infection Control and Laboratory Medicine, Kyoto Prefectural University of Medicine, Kyoto 602-8566, Japan, Tel: +81-75-251-5852; Fax: 81-75-251-5678; E-mail: inaba178@koto.kpu-m.ac.jp

Received February 03, 2014; Accepted February 22, 2014; Published February 28,2014

Citation: Inaba T, Okamoto $\mathrm{Y}$, Yamazaki S, Takatani T, Satoh N, et al. (2014) Hemolytic Anemia with Fragmented Red Blood Cells Following Vascular Access Grafting for Hemodialysis in a Patient with Chronic Kidney Disease. J Blood Disorders Transf 5: 201. doi: 10.4172/21559864.1000201

Copyright: () 2014 Inaba T, et al. This is an open-access article distributed under the terms of the Creative Commons Attribution License, which permits unrestricted use, distribution, and reproduction in any medium, provided the original author and source are credited. 
Citation: Inaba T, Okamoto Y, Yamazaki S, Takatani T, Satoh N, et al. (2014) Hemolytic Anemia with Fragmented Red Blood Cells Following Vascular Access Grafting for Hemodialysis in a Patient with Chronic Kidney Disease. J Blood Disorders Transf 5: 201. doi: 10.4172/21559864.1000201

Page 2 of 2

but ADAMTS13 activity was not examined. Concerning the etiology of anemia, both the Coombs test and osmotic fragility test were negative. From these findings, he was diagnosed with mechanical hemolytic anemia with fragmented $\mathrm{RBC}$, probably caused by arterio-venous bypass grafting. His anemia was persistent, and RBC transfusion had only a transient effect. On the other hand, hemodialysis itself could be sufficiently continued using his arterio-venous bypass graft, suggesting that it is not constitutional problems, such as thrombotic stenosis, but functional disproportion of the blood flow that might lead to the fragmentation of RBC. Therefore, he underwent surgical banding of his left brachial artery just proximal to the anastomotic site of the bypass graft to reduce the blood flow entering the artificial vascular access graft (Figure 2). After this simple operation, the serum LDH level was markedly decreased and had normalized within 1 month. On the other hand, his Hb gradually increased, and exceeded $12 \mathrm{~g} / \mathrm{dL}$ in January 2012

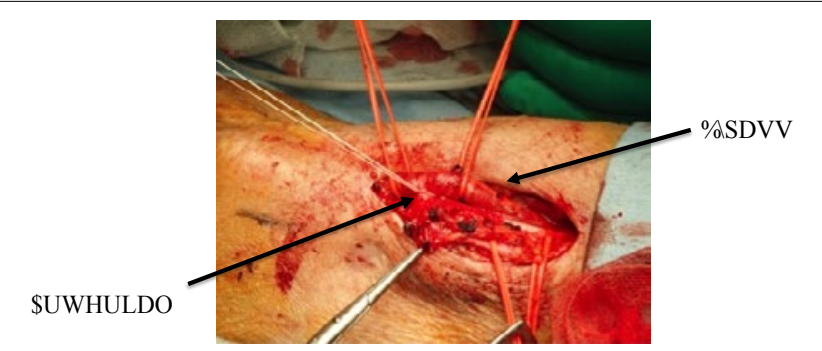

Figure 2: Arterial banding just proximal to the anastomotic site of the bypass graft in his left upper arm.

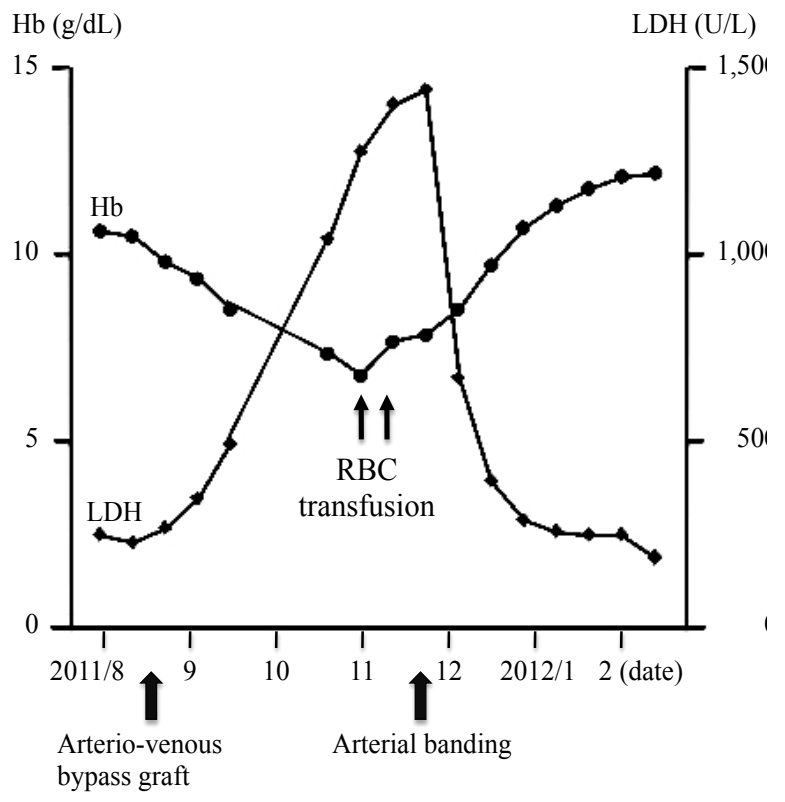

Figure 3: Clinical course of the present patient.
(Figure 3). He has been well controlled so far, without the recurrence of hemolytic anemia, shunt failure, and left brachial ischemia due to arterial banding.

\section{Discussion}

In this paper, we presented a hemodialysis patient who suffered from hemolytic anemia with fragmented RBC after arterio-venous bypass grafting in the upper arm. Angiopathic hemolytic anemia with fragmented RBC has sometimes been reported in patients who have received major cardiovascular surgeries, such as mechanical aortic valve replacement $[3,4]$. On the other hand, Upalakalin et al. reported a patient with microangiopathic hemolytic anemia following mitral valve annuloplasty where the native valve was left in place but repaired [6]. They concluded that mechanical damage to RBC occurred because of blood flow disturbance, with the rapid acceleration and deceleration of the regurgitant jet, and high shear stress on the RBC [6]. Other authors have also reported the hemolytic anemia as the potential complication of mitral valve repair $[7,8]$.

On the other hand, to our knowledge, angiopathic hemolytic anemia with fragmented RBC has not been reported in patients after vascular access grafting for hemodialysis. We should never forget that the functional disproportion of blood flow entering a vascular access graft may cause mechanical hemolytic anemia with RBC fragmentation in patients receiving hemodialysis

\section{References}

1. Eaton JW, Leida MN (1985) Hemolysis in chronic renal failure. Semin Nephrol 5: 133-139.

2. Paganini EP (1989) Overview of anemia associated with chronic renal disease primary and secondary mechanisms. Semin Nephrol 9: 3-8.

3. Manny J, Manny N, Abu-Dallo K, Polliack A, Cohen O, et al. (1997) Traumatic hemolysis after aortofemoral bypass. a study of 25 cases. Israel J Med Sci 13 50-54

4. el-Reshaid K, Kapoor M, Shuhaiber H (1992) Decreased aortic valve prosthesis-associated haemolysis after changing from haemodialysis to peritoneal dialysis. Nephron 62: 90-92.

5. Allen RD, Yuill E, Nankivell BJ, Francis DM (1996) Australian multicentre evaluation of a new polyurethane vascular access graft. Aust N Z J Surg 66: 738-742.

6. Upalakalin JN, Uhl L, Burger AJ (2002) Mitral-valve-induced microangiopathic hemolytic anemia. Transfusion 42: 1105.

7. Demirsoy E, Yilmaz O, Sirin G, Baran T, Tekin S, et al. (2008) Hemolysis after mitral valve repair: a report of five cases and literature review. J Heart Valve Dis 17: $24-30$.

8. Acharya D, McGiffin DC (2013) Hemolysis after mitral valve repair. J Card Surg 28: $129-132$.
Citation: Inaba T, Okamoto Y, Yamazaki S, Takatani T, Satoh N, et al. (2014) Hemolytic Anemia with Fragmented Red Blood Cells Following Vascular Access Grafting for Hemodialysis in a Patient with Chronic Kidney Disease. J Blood Disorders Transf 5: 201. doi: 10.4172/21559864.1000201 